\title{
Properties and microstructure of elements made by electron beam rapid prototyping process with wire
}

\section{Keywords:}

rapid prototyping;

electron beam;

stainless steels

\begin{abstract}
In the paper the results of research on rapid prototyping using electron beam and deposited material in the form of wire are presented. Electron beam rapid prototyping with wire is an efficient method for manufacturing complex shapes from metal alloys such as alloy steels, nickel alloys or titanium. This technology is used primarily in the aviation industry, especially in the military as it is designed rather for a unit production or small series production. As part of the work, technological conditions of the process for which it is possible to deposit test pieces in the form of rectangular prism were determined. Test elements were made using a stainless steel wire grade G $188 \mathrm{Mn}$. Metallographic examinations and selected mechanical properties were investigated. The deposited material is characterized by austenitic with ferrite delta, cell-dendritic microstructure. There are large dendritic grains which are extended towards the heat dissipation - towards the substrate. The hardness in the deposited material is in the range of 192 to $273 \mathrm{HV} 0.05$ depending on the number of layers. In the area

of mixing with the substrate, the hardness reaches the value of $355 \mathrm{HV} 0.05$.
\end{abstract}

\section{Introduction}

Rapid prototyping using electron beam (EBAM - Electron Beam Additive Manufacturing) and deposited material in the form of wire is a modern technology that allows the creation of an element with a given geometry from metal alloys. The depositing process is usually carried out in a vacuum [1], there are also devices enabling the manufacture of elements at atmospheric pressure [2]. The technology is mainly used for depositing titanium alloys [3,4], corrosion resistant steels [4], nickel alloys [5] and aluminum [6]. Gradient materials can also be produced depending on the chemical composition of the substrate and deposited material [7]. In relation to the technology which uses powder as deposited material it is characterized by: less dustiness of the workplace, higher yield of deposited material, higher efficiency, lower porosity of the material in the finished element. The technology also has its limitations, such as: a narrower assortment of deposited alloys, difficulties in the production of elements with a complex shape, higher minimum thickness of the manufactured element, limitations in the production of gradient materials. In addition, in the case of manufacturing thin-walled elements, it is also important to control the deformations, which in the case of the use of additional material in the form of wire are greater [8].

In order to broaden the spread of EBAM technology, it is necessary to determine the impact of individual technological parameters of the process on its stability and geometric features of individual deposited layers. In addition, it is necessary to carry out tests of mechanical properties of manufactured elements and metallographic examination. In essence, the EBAM process is similar to electron beam padding. A detailed analysis of the surfacing process was presented in earlier work [9], while the analysis of liquid metal transfer during depositing at work [10].

The purpose of this work was to determine the technological parameters of the process of rapid prototyping with an electron beam using wire as deposited material, enabling the performance of test pieces. In addition, macro and microscopic metallographic examinations as well as mechanical properties tests of the produced material were performed. A stainless steel wire of G $188 \mathrm{Mn}$ grade was used for the tests.

dr inż. Marek St. Węglowski, prof. dr hab. inż. Jan Pilarczyk, mgr inż. Sylwester Błacha, dr inż. Robert Jachym - Institute of Welding, Gliwice, Poland, prof. dr hab. inż. Jan Dutkiewicz, dr inż. Łukasz Rogal - Institute of Metallurgy and Materials of the Polish Academy of Sciences, Cracow, Poland; 


\section{Research methodology}

Technological trials of rapid prototyping using an electron beam were conducted using a $1.2 \mathrm{~mm}$ diameter welding wire made of stainless steel of G $188 \mathrm{Mn}$ grade acc. PN-EN ISO 14343: 2017-06 (LNM307 Lincoln Electric: C 0.07\%, Mn 7.1\%, Si $0.8 \%$, Cr $18.6 \%, \mathrm{Ni} 8.0 \%$ wt.). The substrate consisted of test panels with dimensions of $200 \times 80 \times 10 \mathrm{~mm}$ made of non-alloy steel of S355JR grade. The tests were carried out using a XW150:30/756 (Cambridge Vacuum Engineering) device for welding and surface modification. The device has been equipped with a wire feeder enabling the use of additional materials in the form of a spool weighing up to $15 \mathrm{~kg}$. The surface of the boards prior to depositing was pre-milled and cleaned using acetone. The tests were carried out with a constant positioning of the wire tip with respect to the electron beam. The wire feed angle was $30^{\circ}$ and the pressure inside the chamber was $5 \cdot 10^{-5}$ mbar. Metallographic examinations of deposited elements were made on cross-sections in relation to the direction of depositing. Microstructural investigations were carried out on samples etched in a reagent with the following composition: $100 \mathrm{ml}$ of ethyl alcohol, $100 \mathrm{ml}$ of $\mathrm{HCl}, 5 \mathrm{~g}$ of $\mathrm{CuCl}_{2}$. Phase analysis (Philips PW1710 diffractometer, anoda Co), light microscopy (Eclipse MA 200, Leica DM IRM / Neophot 32 Carl Zeiss) was performed and porosity has been determined using the Carl Zeiss software. Vickers hardness measurements were carried out using a KB50 FA hardness tester (Prüftechnik $\mathrm{GmbH}$ ) according to PN-EN ISO 6507-1: 2018-05. Tests of strength properties of the material were carried out in accordance with the requirements of $\mathrm{PN}$ EN ISO 6892-1: 2016-09 at room temperature.

\section{Test results and analysis}

The aim of the work was to carry out experimental studies on the determination of the technological conditions of the rapid prototyping process using a beam of electrons with an additional material in the form of a solid wire and carrying out metallographic and mechanical tests of the deposited material.

In the first stage of the tests which were carried out, test elements were made (Fig. 1). The results of metallographic examinations for individual deposited layers are shown in Figure 2 . The rapid prototyping process was carried out with the following technological parameters: accelerating voltage $\mathrm{U}=60 \mathrm{kV}$, beam current $\mathrm{I}=15 \mathrm{~mA}$, travelling speed $\mathrm{v}=2000 \mathrm{~mm} / \mathrm{min}$, wire feed speed $\mathrm{v}_{\mathrm{d}}=1000 \mathrm{~mm} / \mathrm{min}$.

Considering the depth of penetration being too deep in the second stage of research, it was decided to reduce the travelling speed to the value of $v=1000 \mathrm{~mm} / \mathrm{min}$. Figure 3 presents sample results of macroscopic metallographic examinations of the obtained test elements.

Reducing the travelling speed resulted in the reduction of the melted zone and influenced the method of heat

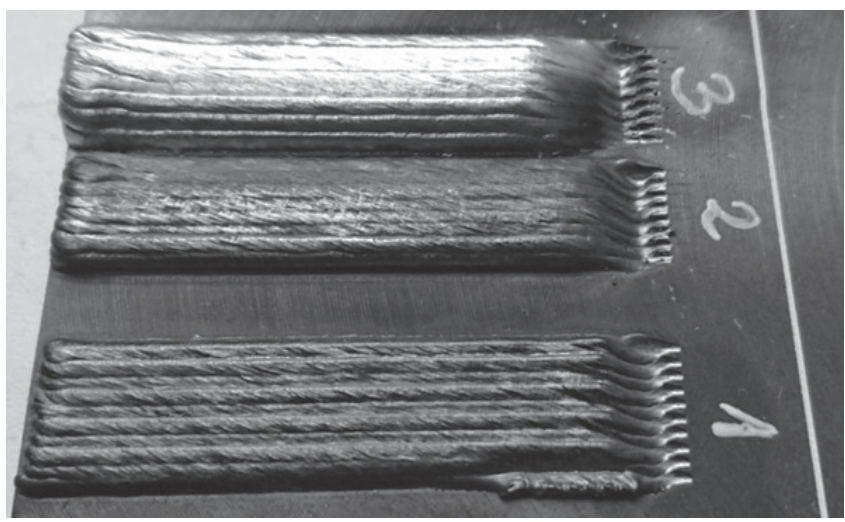

Fig. 1. Deposited test pieces composed of single layer (1), two layers (2) and three layers (3)
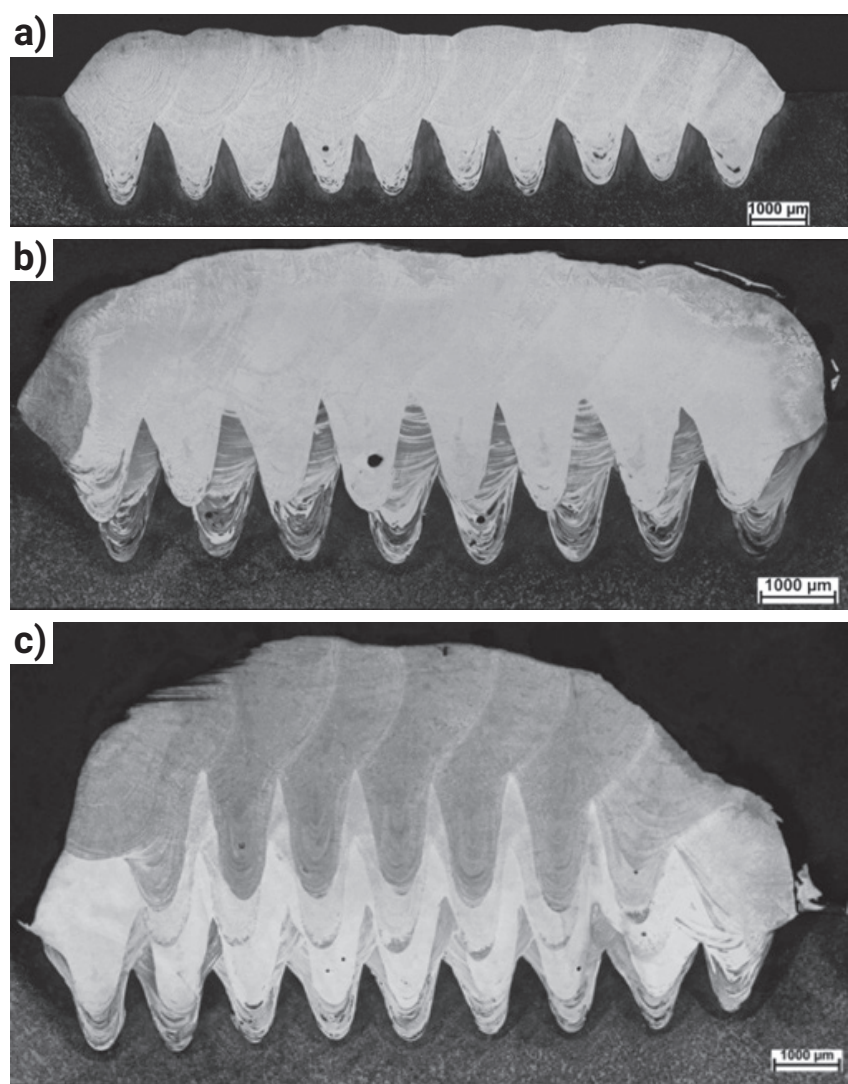

Fig. 2. Macrostructure of deposited layers: a) single layer, b) two lay ers, c) four layers
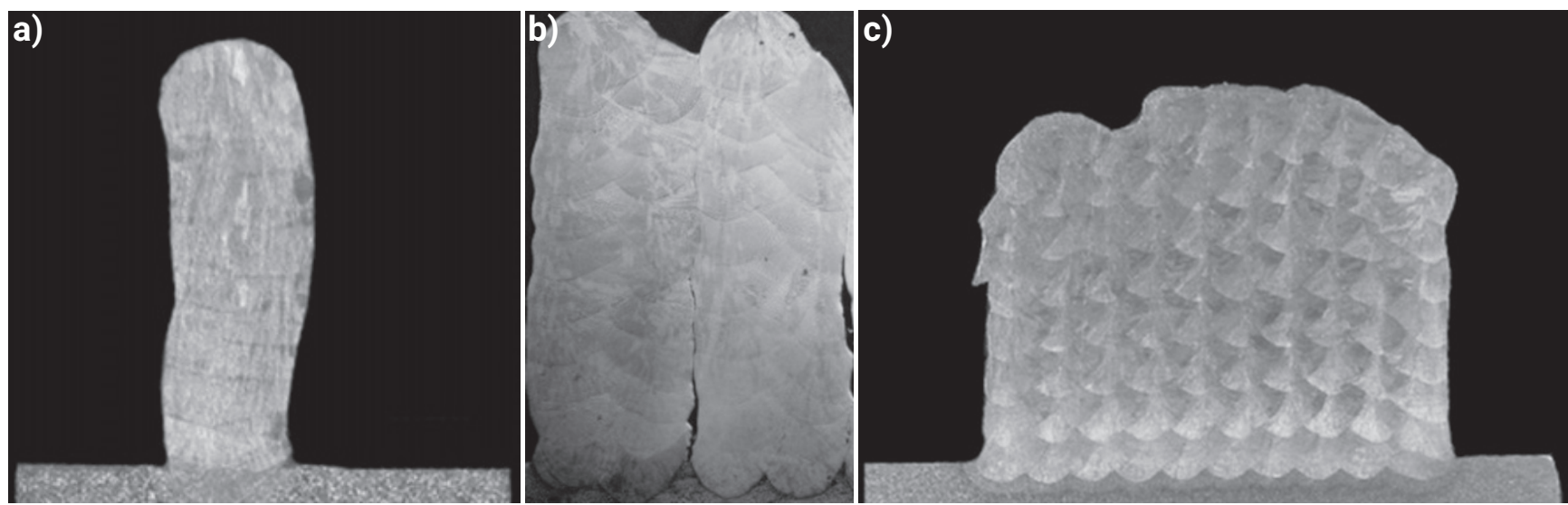

Fig. 3. Macrostructure of deposited test pieces: a) single bead (10 layers), b) four beads (10 layers), c) ten beads (8 layers) 
removal, and thus also the microstructure of the material. The microstructure of materials can be described as cell-dendritic (Fig. 4b). However, due to the reduction of the interaction zone with the electron beam, this microstructure is more homogeneous. There are large dendritic grains which are extended towards the heat draining - towards the substrate. Moreover, the border of remelting zones is not the limit for grain growth (Fig. 4a).

The hardness measurement (Fig. 5) carried out on the cross-section of the samples shown in Figures $3 \mathrm{a}$ and $3 \mathrm{c}$ also indicates that these materials are homogeneous. The hardness in deposited material is from 192 to 245 HV0.05 in a single-walled deposited sample and from 205 to $273 \mathrm{HV} 0.05$ in a sample of 10 layers. In the area of mixing with the substrate, the hardness reaches the value of $350 \mathrm{HV}$ (10 layers). The increase in hardness is related to the change in the chemical composition caused by mixing with the substrate material.
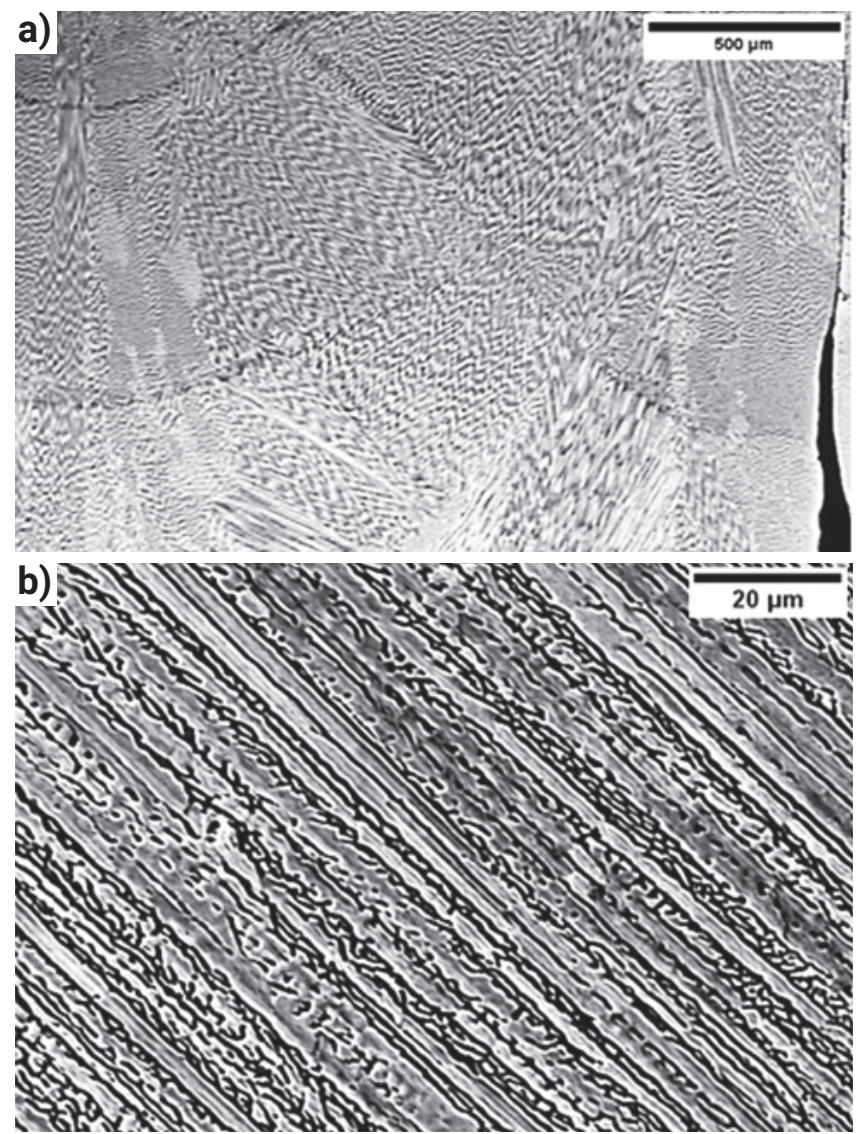

Fig. 4. Typical microstructure of test piece presented in Figure 3b: a) lower magnification, b) higher magnification of the same region

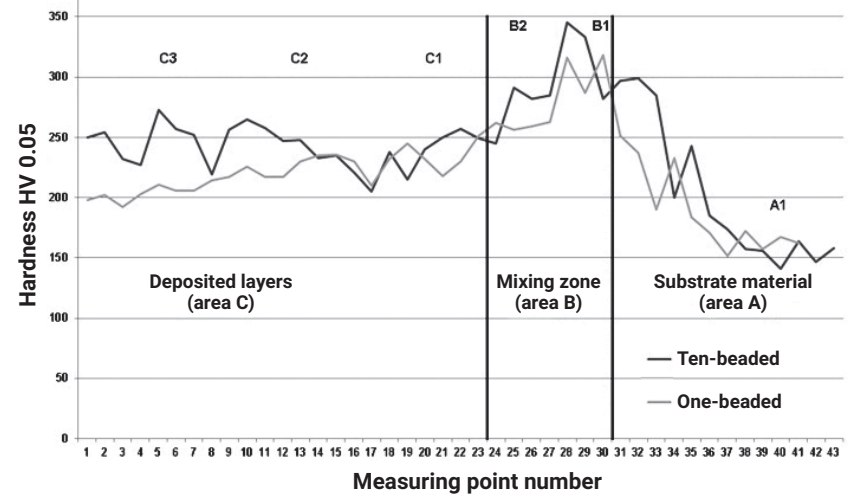

Fig. 5. Hardness profile of test piece presented in Figures 3a and 3c
A phase analysis of materials was also carried out. It showed the coexistence of two phases - the austenite phase (FCC) and ferrite (BCC) - Figure 6. The occurrence of two phase is associated with the dendritic crystallization of the material. During rapid crystallization, chemical segregation occurs - growing dendrites enrich in $\mathrm{Ni}$, while inter-tribal areas in $\mathrm{Cr}$, and then crystallize in the form of a-Fe.

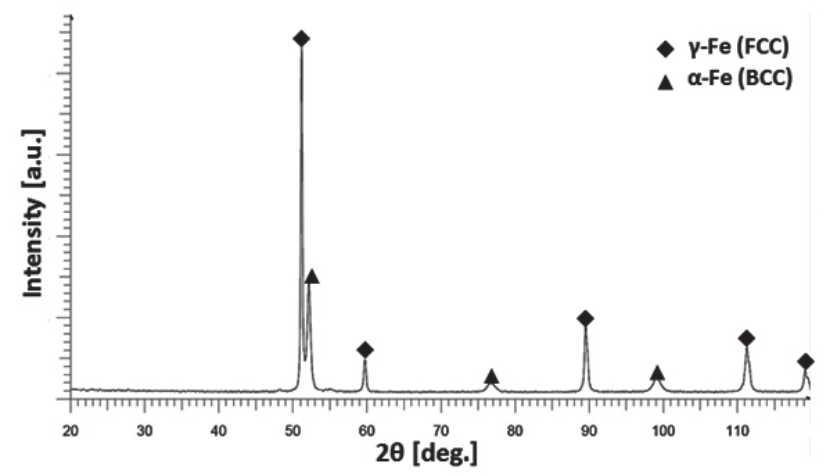

Fig. 6. X-ray diffractometer of test piece presented in Figure 3b

The porosity determined from the cross-sections of the samples is low and does not exceed 1\% (Fig. 7). Observed pores are usually spherical, so they should not have a major impact on the mechanical properties of the materials. The pores are mainly found in the lower parts of the remelting zones and result from the trapping of gas bubbles through the metal during the solidification of the molten metal pool.

The preliminary tests which were carried out allowed the development of EBAM technological parameters and the creation of a test element with larger dimensions $(140 \times 40 \times 20 \mathrm{~mm})$. The element shown in Figure 8 was made by depositing 18 layers, each layer consisted of 42 individual padding welds.

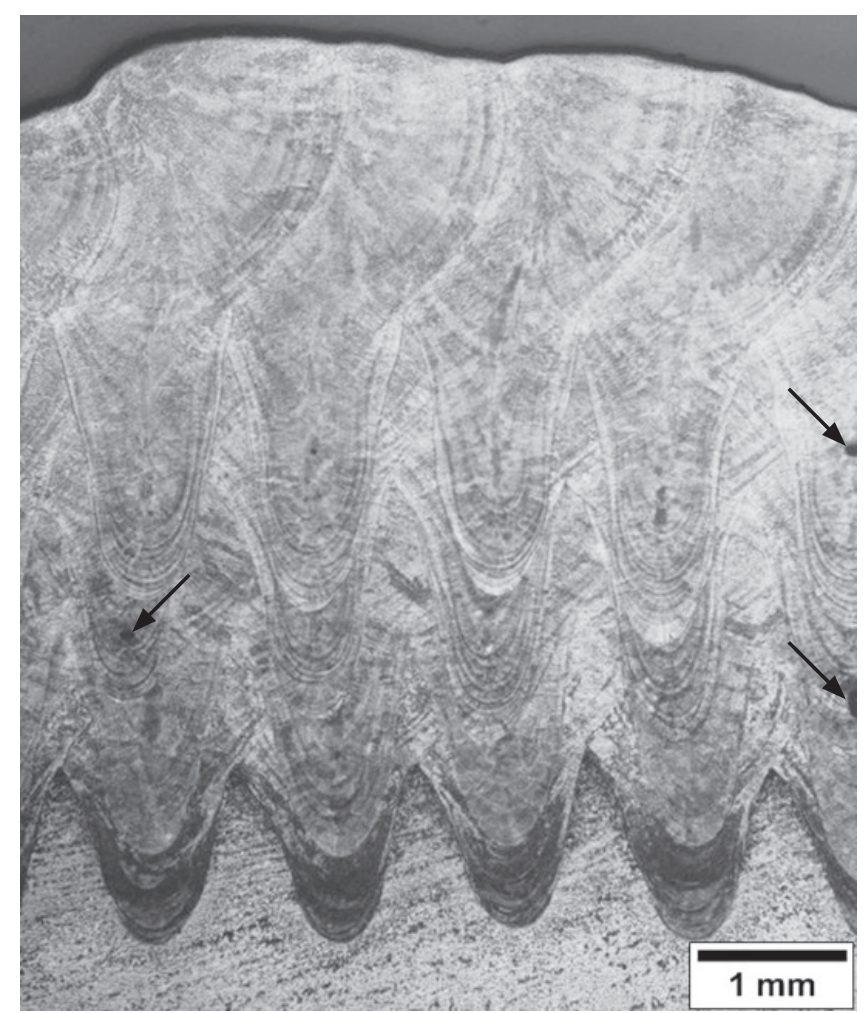

Fig. 7. Microstructure of test piece presented in Figure $3 \mathrm{~b}$ with pores (mark with arrows) 


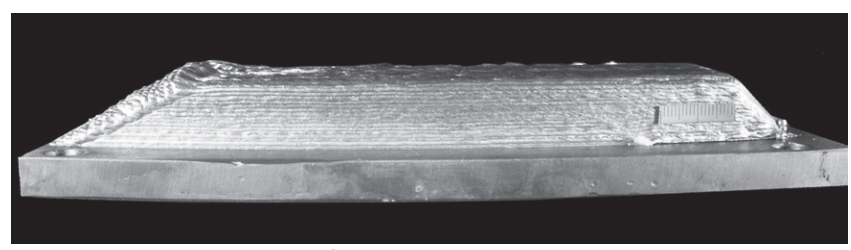

Fig. 8. Test piece made of wire grade G $188 \mathrm{Mn}, 18$ layers, 42 bead in one layer

Samples from the made element were taken for strength tests. Strength tests were carried out on samples with a circular cross-section in accordance with the requirements of PN-EN ISO 6892-1: 2016-09. The aim of the research was to determine the strength and plastic properties of the weld metal. The results of the tests are presented in the Table I. The obtained results were compared with the mechanical properties of the additional material - corrosion-resistant steel wire of LNM307 grade (Lincoln Electric).

The tests carried out showed that the weld metal strength properties for the electron beam meet the requirements specified by the manufacturer. The definitely higher strength of the weld metal obtained most probably results from different heating and cooling conditions during the EBAM process compared to processes carried out with typical arc methods (e.g. MIG). Strength properties presented in the test were determined for MIG welding technology.

Table I. Results of tests of the strength properties of the weld metal

\begin{tabular}{|c|c|c|c|c|c|c|c|}
\hline \multirow{2}{*}{$\begin{array}{l}\text { Designation } \\
\text { of the sample }\end{array}$} & \multicolumn{3}{|c|}{ Dimensions of the sample } & \multirow{2}{*}{ YS [MPa] } & \multirow{2}{*}{ UTS [MPa] } & \multirow{2}{*}{$\mathbf{A}_{5}[\%]$} & \multirow{2}{*}{$\begin{array}{l}\text { Comments } \\
\text { on the breakthrough } \\
\text { of the sample }\end{array}$} \\
\hline & $\mathrm{d}_{0}[\mathrm{~mm}]$ & $\mathrm{L}_{0}[\mathrm{~mm}]$ & $\mathrm{S}_{0}\left[\mathrm{~mm}^{2}\right]$ & & & & \\
\hline $\mathrm{R} / 1$ & 9,95 & 50 & 77,7 & 574,6 & 720,7 & 39,2 & Plastic breakthrough \\
\hline $\mathrm{R} / 2$ & 9,97 & 50 & 78,0 & 581,0 & 723,1 & 37,6 & Plastic breakthrough \\
\hline LNM 307 & - & - & - & $400^{*}$ & $630 *$ & $40^{\star}$ & - \\
\hline
\end{tabular}

\section{Conclusions}

The following conclusions can be drawn on the basis of the research:

- the process of rapid prototyping using a beam of electrons with deposited material in the form of wire enables the fabrication of test elements with strictly defined technological parameters;

- deposited material is characterized by cell-dendritic microstructure. There are large dendritic grains, which are extended towards the heat draining - towards the substrate;

- the hardness in deposited material is from 192 to 245 HV0.05 in a single-walled deposited sample and from 205 to 273 HV0.05 in a sample of 10 layers. In the area of mixing with the substrate, the hardness reaches the value of $355 \mathrm{HV} 0.05$;

- strength properties of the weld metal for the electron beam meet the requirements specified by the manufacturer, and the strength is higher by $90 \mathrm{MPa}$ in relation to the data presented in the certificate.

The presented research results are the effect of the project entitled: "Multiscale analysis of physical and chemical processes during rapid prototyping using concentrated energy sources in view of formation of microstructure and mechanical properties" no. of the contract UMO-2016/23/B/ST8/00754 financed by the National Science Center, Poland.

\section{References}

[1] M.St. Węglowski, Szybkie prototypowanie przy użyciu wiązki elektronów - stan wiedzy, Biuletyn Instytutu Spawalnictwa (2018), vol. 62(1), 29-35.

[2] G. Klimov, N. Murray, Additive manufacturing using non-vacuum electron beam technology, Proceeding of 4th IEBW International Electron Beam Conference Aachen (2017), 99-103.

[3] T.M. Butler and others, Evolution of Texture from a Single Crystal Ti-6Al-4V Substrate During Electron Beam Directed Energy Deposition, Metallurgical And Materials Transactions A (2017), vol. 48A, 4441-4446.

[4] B. Baufeld, R. Widdison, T. Dutilleu: Electron beam additive manufacturing: Deposition strategies and properties, Proceeding of 4th IEBW International Electron Beam Conference Aachen (2017), 114-117.

[5] M.E. Kinsella, Additive Manufacturing of Superalloys for Aerospace Application, Air Force Research Laboratory Report No AFRL-RX-WP-TP-2008-4318:1-7 (2008).
[6] K.M.B. Taminger, R.A. Hafley, Electron beam freeform fabrication for cost effective near net shape manufacturing. AVT-139, NATO, https://ntrs.nasa. gov/archive/nasa/casi.ntrs.nasa.gov/20080013538.pdf, 2006.

[7] X. Shu, G. Chen and others, Microstructure evolution of copper/steel gradient deposition prepared using electron beam freeform fabrication, Materials Letters (2018), vol. 213, 374-377.

[8] Z. Chen, H. Ye and others, Distortion control in a wire-fed electron-beam thin-walled Ti-6Al-4V freeform, Journal of Materials Processing Technology (2018), vol. 258, 286-295.

[9] M.St. Węglowski, S. Błacha, Napawanie wiązką elektronów przy użyciu drutu, Przegląd Spawalnictwa (2017), vol. 89(10), 47-51.

[10] J. Zhao, B. Zhang, A. Li and others, Effects of metal-vapor jet force on the physical behavior of melting wire transfer in electron beam additive manufacturing, Journal of Materials Processesing Technology (2015), vol. 220, 243-25. 